\title{
Differential Expression of DNA Nonhomologous End- Joining Proteins Ku70 and Ku80 in Melanoma Progression
}

\author{
Monika Korabiowska, M.D., Michael Tscherny, M.D., Jerzy Stachura, M.D., Ph.D., \\ Hermann Berger, M.D., Ph.D., Carlos Cordon-Cardo, M.D., Ph.D, Ulrich Brinck, M.D., Ph.D. \\ Departments of Cytopathology (MK, MT), Dermatohistology (HB), and Gastroenteropathology (UB), University \\ of Göttingen, Göttingen, Germany; Department of Pathology, Jagiellonian University, Cracow, Poland (JS); and \\ Division of Molecular Pathology, Memorial Sloan-Kettering Cancer Center, New York (CC-C)
}

Ku70 and Ku80 heterodimers function as regulatory subunits of the DNA-dependent protein kinase and play a very important role in the repairing of DNA double-strand breaks. Although Ku70 is proposed as a candidate for a tumor suppressor gene, not many data are available on Ku70 and Ku80 expression in human tumors. The main aim of this study was to investigate the expression of Ku70 and Ku80 in the ultravioletinduced lesions-nevus cell nevi, lentigos maligna, and malignant melanomas. Nineteen nevus cell nevi, 23 lentigos maligna, 76 primary melanomas, and 31 melanoma metastases were stained immunohistochemically for the presence of Ku70 and Ku80 proteins. Ku70 and Ku80 expression was preserved in about $80 \%$ of nevi, $26 \%$ of lentigo maligna, $45 \%$ of primary melanomas, and $67 \%$ of melanoma metastases. Highly significant differences in Ku70 and Ku80 expression were found between nevi, lentigo maligna, and melanomas. In Cox regression, Ku70 and Ku80 were shown to be highly significant influences on patients' prognosis. Significant correlations between Ku70 and Ku80 expressions were found in nevi, lentigo maligna, and primary melanomas. These correlations were not more present in melanoma metastases. To summarize, earlier phases of melanoma progression seem to be connected with the loss of expression of Ku proteins. Metastatic spread is related to dysregulation of the Ku70 and Ku80 axis.

KEY WORDS: DNA repair, Ku 70, Ku 80, Melanoma. Mod Pathol 2002;15(4):426-433

Copyright $(2) 2002$ by The United States and Canadian Academy of Pathology, Inc

VOL. 15, NO. 4, P. 426, 2002 Printed in the U.S.A.

Date of acceptance: December 20, 2001.

Address reprint requests to: Monika Korabiowska, M.D., Department of Cytopathology, Georg-August University of Göttingen, Robert Koch

Strasse 40, 37075 Göttingen, Germany; fax: 01149551398641.
DNA double-strand damage is most frequently induced by ionizing radiation, and in mammalian cells, this damage can be repaired by several pathways including homologous recombination and nonhomologous end joining (1-3). DNA-dependent protein kinase plays a major role in the repair of double-strand breaks and consists of a regulatory subunit (Ku70 and Ku80 heterodimer) and catalytic subunit (4-6). Ku70 and Ku80 genes are caretaker genes involved in nonhomologous end joining and are active mainly during G1 and early S-phase $(7,8)$. Ku70 is proposed as a candidate for a tumor suppressor gene. According to Li et al. (9), inactivation of the Ku70 gene can lead to a propensity for malignant transformation both in vitro and in vivo. The mechanism by which Ku70 exerts its action in human cells is still a subject of discussion. In yeasts, Ku70 protein regulates adaptation to G2/M arrest after DNA damage (10). The role of Ku80 protein in tumor biology is so far unclear. However, cells with increased Ku70 and Ku80 expression are reported to exhibit hypersensitivity to genotoxic drugs, such as cisplatin and adu'amycin $(11,12)$. Ku70 and Ku80 heterodimers seem to be functionally connected not only with malignant disease; Ku70 and Ku80 autoantibodies were found in the serum of lupus erythematosus patients $(13,14)$.

Although many biochemical details on Ku70 and Ku80 proteins are available, there are not many data on Ku70 and Ku80 DNA-binding activity in human tumors.

In the light of the major role that Ku70 and Ku80 proteins play in the repair of double-strand breaks induced in DNA after ionizing radiation, we decided to investigate the expression of $\mathrm{Ku}$ proteins in different steps of melanoma progression from nevus to melanoma metastases. We selected melanocytic tumors for our study because of the close connection between melanoma etiology and ultraviolet exposure (15-20). 


\section{MATERIALS AND METHODS}

Material investigated consisted of 19 nevus cell nevi, 23 lentigos maligna, 76 primary melanomas, 18 melanoma lymphatic metastases, and 13 melanoma metastases to vital organs.

Primary melanoma patients were treated at the teaching hospital of the University of Cracow, Cracow, Poland between 1993 and 1995. The anatomic localization of primary melanomas was distributed as follows: head and neck $(n=13)$, trunk $(n=27)$, upper extremities $(n=17)$, and lower extremities ( $n$ $=19$ ). All primary melanomas were classified according to the criteria of Breslow (21). Tumor thickness varied between 0.26 and $8.4 \mathrm{~mm}$, averaging $2.93 \mathrm{~mm}$. All patients were monitored from the time of diagnosis up to the end of the study (January 1 , 2000). Data on the clinical course of the patients were collected from the attending physicians.

Of a total of 149 patients, 63 were women and 86 were men. The age of the patients ranged between 23 and 87 years, averaging 56 years.

\section{Immunohistochemistry}

Immunohistochemistry was performed by using $5-\mu \mathrm{m}$ paraffin sections that were deparaffinized in xylene (three times for 5 min each) and rehydrated in decreasing concentrations of ethanol (100\%, $96 \%$; two times each for $10 \mathrm{~min}$ ), followed by washing in deionized $\mathrm{H}_{2} \mathrm{O}$ for 1 minute. To unmask the $\mathrm{Ku}$ antigens, the slides were covered with $0.01 \mathrm{M}$ sodium citrate buffer ( $\mathrm{pH}$ 6.0) and placed on a heat plate $\left(95^{\circ} \mathrm{C}\right.$ ) for 10 minutes. After cooling down, the specimens were rinsed briefly in deionized $\mathrm{H}_{2} \mathrm{O}$ (three times). The specific primary (goat polyclonal) antibodies (Ku-70M19; Ku-80-M20; Santa Cruz Biotechnology, Santa Cruz, CA) were applied in a dilution of 1:50 overnight at $4^{\circ} \mathrm{C}$. Both primary antibodies applied were directed against an epitope mapping at the carboxy terminus of the Ku70 and Ku80 proteins.

Reagents I-V used on the second day were supplied in the ImmunoCruz Staining System (Santa Cruz Biotechnology). Each of these reagents was prediluted and ready to use at room temperature. After extensive washing with $0.02 \mathrm{M}$ Tris-phosphate buffer ( $\mathrm{pH} 7.2$ ), the immunoreactivity was detected with a biotinylated secondary antibody [I] by incubating the specimens for 30 minutes at room temperature. Slides were rinsed with Tris-phosphate buffer for 5 minutes before a horseradish peroxidase-streptavidin complex [II] was added for 30 minutes. Washing in Trisphosphate buffer for 5 minutes followed. Subsequently, color was developed by using a horseradish peroxidase substrate (mixture of $1.6 \mathrm{~mL}$ of deionized $\mathrm{H}_{2} \mathrm{O}, 250 \mu \mathrm{L}$ of $10 \times$ substrate buffer [III], $50 \mu \mathrm{L}$ of $50 \times$ 3,3 '-diaminobenzidine chromogen [IV], and $50 \mu \mathrm{L}$ $50 \times$ peroxidase substrate $[\mathrm{V}])$ that was applied on the sections until light brown staining was visible (approximately $10 \mathrm{~min}$ ). Samples were washed again in deionized $\mathrm{H}_{2} \mathrm{O}$, then counterstained with hematoxylin, dehydrated (increasing concentrations of ethanol: $96 \%$ and $100 \%$; followed by xylene, twice each for $10 \mathrm{~s}$ ) and mounted in DePeX (Merck, Whitehouse Station). For negative-control staining, the primary antibodies were omitted. For quantification of the tumor cells with a positive staining, the CAS200 image analyzer (Becton-Dickinson, Hamburg, Germany) was used, and results were expressed as percentages of positive cells (indices).

\section{Statistics}

The minimum, 25th percentile, median, 75th percentile, and maximum of Ku70 and Ku80 indices were calculated for each diagnostic group investigated. Comparison of groups was performed by applying the Mann-Whitney $U$ test. The relation between markers was analyzed by using the correlation coefficient according to Spearman.

The Kaplan-Meier method was employed to calculate the survival rates (22). The significance of the difference in the survival curves was calculated with the log-rank tests. Cox regression was the multivariate method used for predicting the survival rate based on several parameters (23). Cox regression was used repeatedly to explore the set of data. The data set was modeled using the methods offered by the SPSS forward selection and backward selection. The first method adds parameters to a survival prediction model until the exclusion criterion is reached. By contrast, backward selection eliminates parameters from the model until the inclusion criterion is reached. The terminate criteria (for inclusion and exclusion) was the likelihood ratio based on partial likelihood estimators. In general, Cox regression helps provide a formula for predicting the survival and testing the significance of individual predictors.

\section{RESULTS}

\section{Localization of Reaction Product}

Ku70 and Ku80 immunostaining demonstrated nuclear reaction product. Normal structures (cells in basal and spinous layer of epidermis, normal melanocytes) served as positive controls (Fig. 1A).

\section{Ku70 Expression in Diagnostic \\ Groups Investigated}

Ku70 expression was found in $83 \%$ of nevus cell nevi, $30 \%$ of lentigo maligna, $59 \%$ of primary melanomas (Fig. 1B), 67\% melanoma metastases in lymph nodes, and $69 \%$ of melanoma metastases in vital organs (Table 1). The Ku70 indices (percentage of Ku70-positive cells) peaked at $70 \%$ in nevi, $10 \%$ in lentigo maligna, $40 \%$ in primary melanomas and 
melanoma metastases in lymph nodes, and 35\% in melanoma metastases in vital organs (Fig. 2).

\section{Ku80 Expression in Diagnostic Groups Investigated}

Ku80 expression was observed in $78 \%$ of nevi, $26 \%$ of lentigo maligna, $45 \%$ of primary melanomas (Fig. $1 C), 67 \%$ of melanoma metastases in lymph nodes, and $69 \%$ of melanoma metastases in vital organs (Table 1). The Ku80 indices (percentage of Ku80-positive cells) did not exceed $50 \%$ in nevi, $10 \%$ in lentigo maligna, $40 \%$ in primary melanomas, and $30 \%$ in melanoma metastases in lymph nodes or vital organs (Fig. 3).

\section{Comparison of Diagnostic Groups Investigated} with Regard to Ku70 and Ku80 Expression

Highly significant differences in Ku70 expression were found between nevi and lentigo maligna as

a
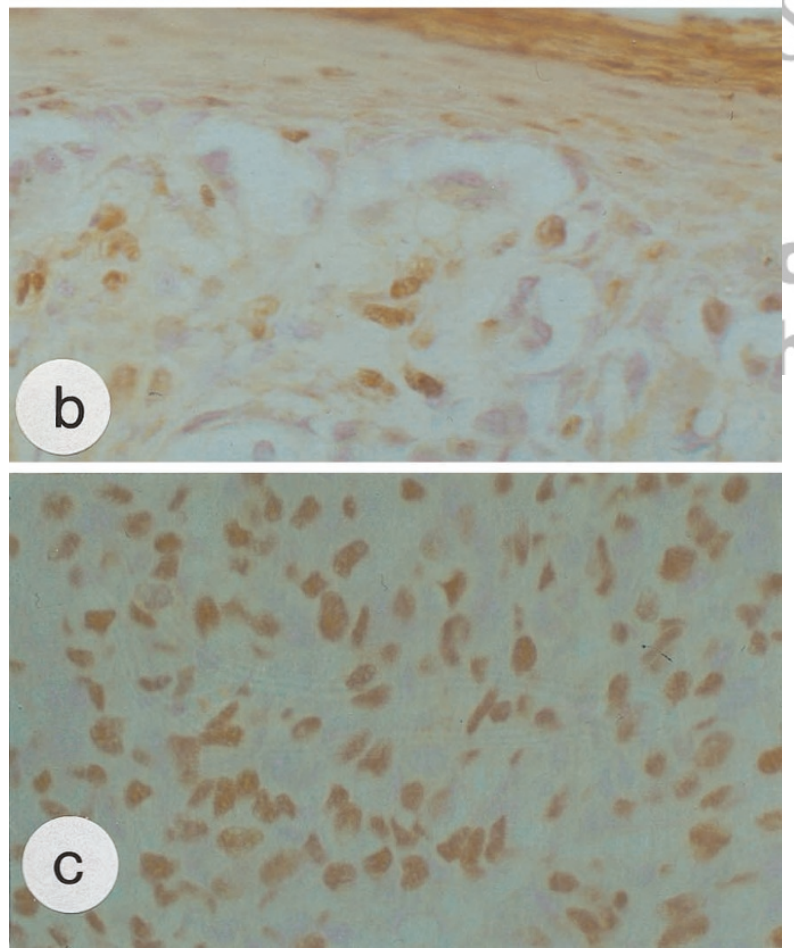

FIGURE 1. A, Ku70 positivity in normal epidermis $(400 \times)$. B, Ku70positive staining in primary melanoma $(400 \times)$. C, Ku80 immunopositivity in primary tumor $(400 \times)$
TABLE 1. Percentage of Ku70/80-Positive Cases in the Diagnostic Groups Investigated

\begin{tabular}{lcc}
\hline \multirow{2}{*}{ Diagnosis } & \multicolumn{2}{c}{ \% of Tumors Positive for } \\
\cline { 2 - 3 } & Ku70 & Ku80 \\
\hline Naevi & 83 & 78 \\
Lentigo maligna & 30 & 26 \\
Primary melanomas & 59 & 45 \\
Lymphatic metastases & 67 & 67 \\
Organ metastases & 69 & 69 \\
\hline
\end{tabular}

well as between nevi and primary melanomas and between lentigo maligna and primary melanomas. Differences in Ku70 expression between primary melanomas and both types of melanoma metastases did not reach significance. Neither were there found any significant differences between melanoma metastases in lymph nodes and vital organs concerning Ku70 expression $(P>.05)$.

Similar differences were found for Ku80 expression, with only one exception: the difference between lentigo maligna and primary melanomas was not significant $(P>.05)$.

\section{Relation between Ku70 Expression and Tumor Thickness Classified According to Breslow and pT Category}

Ku70-positive cells were found in $100 \%$ of pT1 tumors, $68 \%$ of pT2 tumors, $59 \%$ of pT3 tumors, and $33 \%$ of pT4 melanomas (Table 2). The Ku70 index reached a maximum of $50 \%$ (Fig. 4). Comparison of $\mathrm{pT}$ levels did not show any significant differences with rēgărd to Ku70 expression.

\section{Relation between Ku80 Expression and Tumor Thickness Classified According to Breslow and pT Category}

Ku80 positivity was found in $100 \%$ of pT1 melanomas, $40 \%$ of pT2 tumors, $41 \%$ of pT3 tumors, and $33 \%$ of pT 4 tumors (Table 2). Ku80 index peaked at $40 \%$ in pT 1 and pT2 melanomas and at $30 \%$ in pT3 and pT4 melanomas (Fig. 5). Comparison of pT levels did not demonstrate any significant differences with respect to Ku80 expression.

\section{Prognostic Significance of Ku70 and Ku80 Proteins}

\section{Ku70}

Thirteen percent of Ku70-negative cases and 63\% of Ku70-positive cases survived for $>5$ years. This difference was highly significant $(P<.01$; Fig. $6 \mathrm{~A})$.

\section{Ku80}

Seventy percent of patients with Ku80-positive melanomas and only $15 \%$ of patients with Ku80-negative melanomas survived for $>5$ years. This difference was also highly significant $(P<.01$; Fig. $6 \mathrm{~B})$. 


\section{KU 70 Expression}

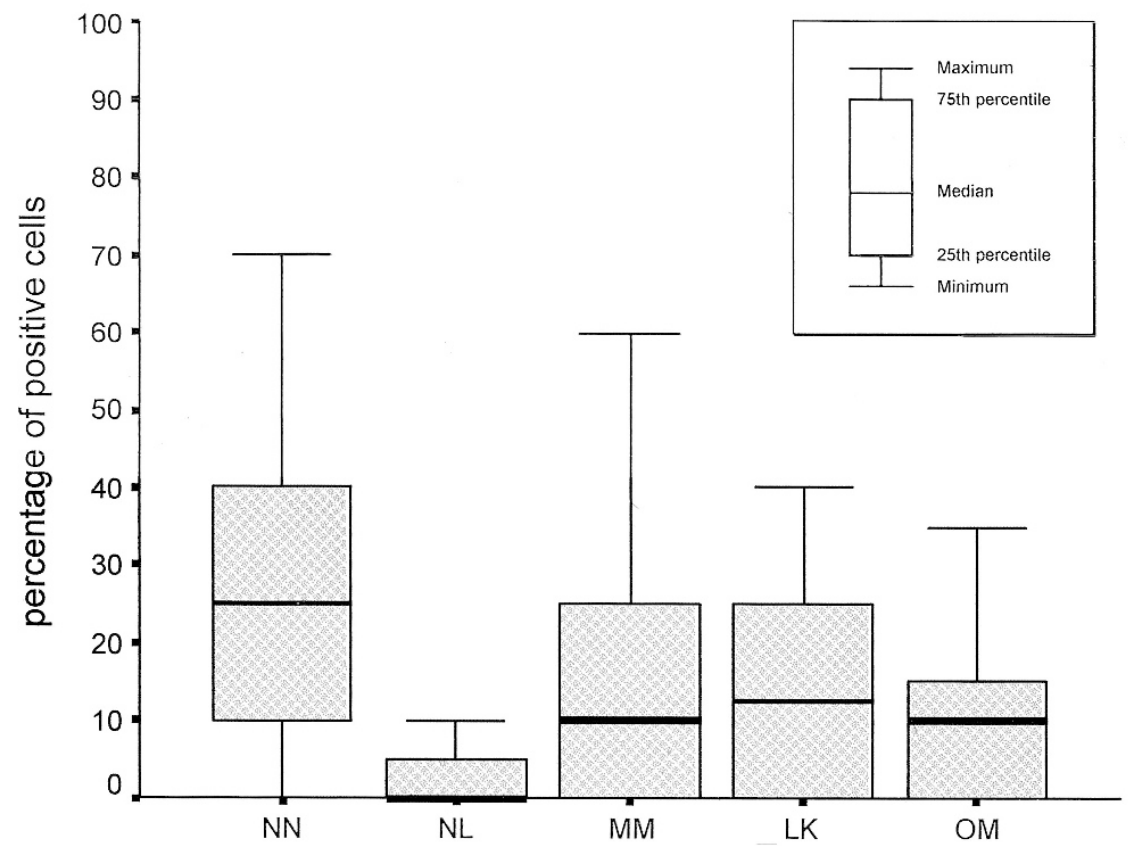

FIGURE 2. Box plot showing the values of Ku70 index in diagnostic groups investigated. NN, nevus cell nevi; NL, lentigo maligna; MM, primary melanomas; LK, lymphatic metastases; OM, organ metastases.

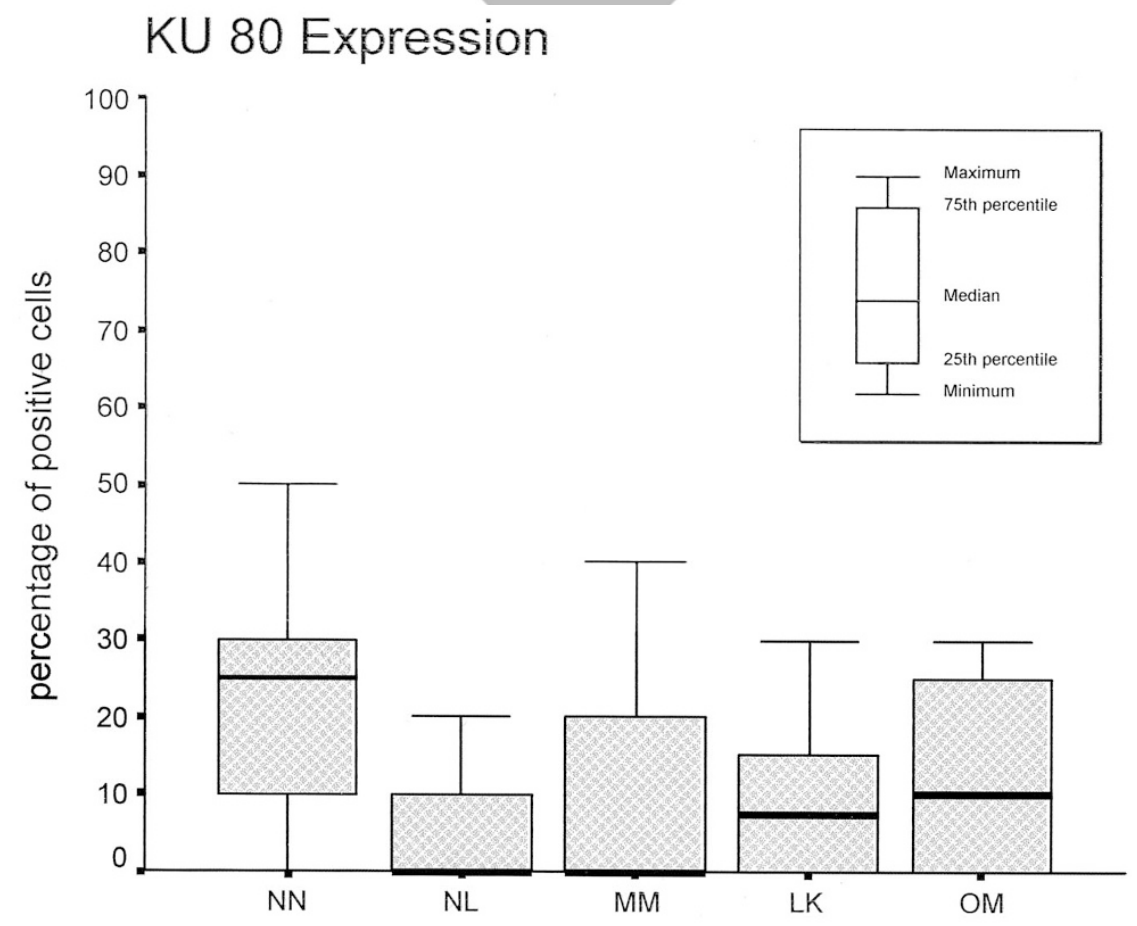

FIGURE 3. Box plot showing the values of Ku80 index in diagnostic groups investigated. NN, nevus cell nevi; NL, lentigo maligna; MM, primary melanomas; LK, lymphatic metastases; OM, organ metastases.

As a next step, we compared the 5-year survival rate of Ku70- and Ku80-negative cases with either Ku70- or Ku80-positive cases. As for single markers mentioned before, this difference was also significant $(P<.01$; Fig. 7$)$.

\section{Cox Regression}

According to Cox regression results, both Ku proteins demonstrated an independent prognostic impact in forward (Ku70: $P<.001$; coefficient of regression, -0.1102 ; change of risk, $-10 \%$; confi- 
TABLE 2. Ku70/80 Expression in Primary Melanomas Classified According to BRESLOW (21) and pT

\begin{tabular}{ccc}
\hline \multirow{2}{*}{ pT $(\mathrm{mm})$ Category } & \multicolumn{2}{c}{ Percentage of Cases Positive for } \\
\cline { 2 - 3 } & Ku70 & Ku80 \\
\hline pT1 $(<0.75)$ & 100 & 100 \\
pT2 $(0.75-1.5)$ & 68 & 40 \\
pT3 $(1.5-4.0)$ & 59 & 41 \\
pT4 $(>4.00)$ & 33 & 33 \\
\hline
\end{tabular}

dence limits, $-14-6 \%$; Ku80: $P<.001$; coefficient of regression, -0.1474 ; change of risk, $-14 \%$; confidence limits, $-20-7 \%$ ) and backward selections (Ku70: $P<.001$; coefficient of regression, -0.1386 ; change of risk, $-13 \%$; confidence limits, $18-8 \%$; Ku80: $P<.001$; coefficient of regression, -0.1618 ; change of risk, $-15 \%$; confidence limits, $-21-8 \%$ ).

\section{KU 70 Expression}

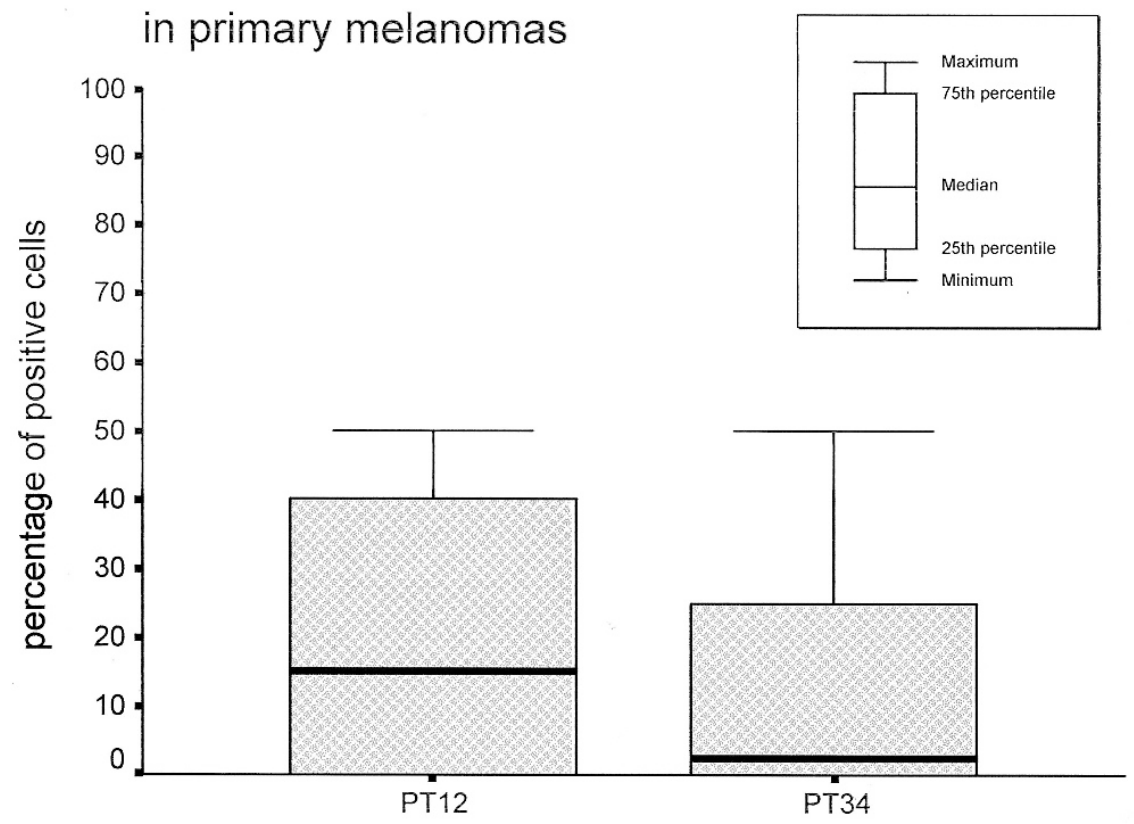

FIGURE 4. Box plot demonstrating the expression of Ku70 in primary melanomas classified according to WHŌ-pT. PT12-melanomas with thickness of $<1.5 \mathrm{~mm}$, PT34-melanomas with thickness of $>1.5 \mathrm{~mm}$

\section{KU 80 Expression}

in primary melanomas

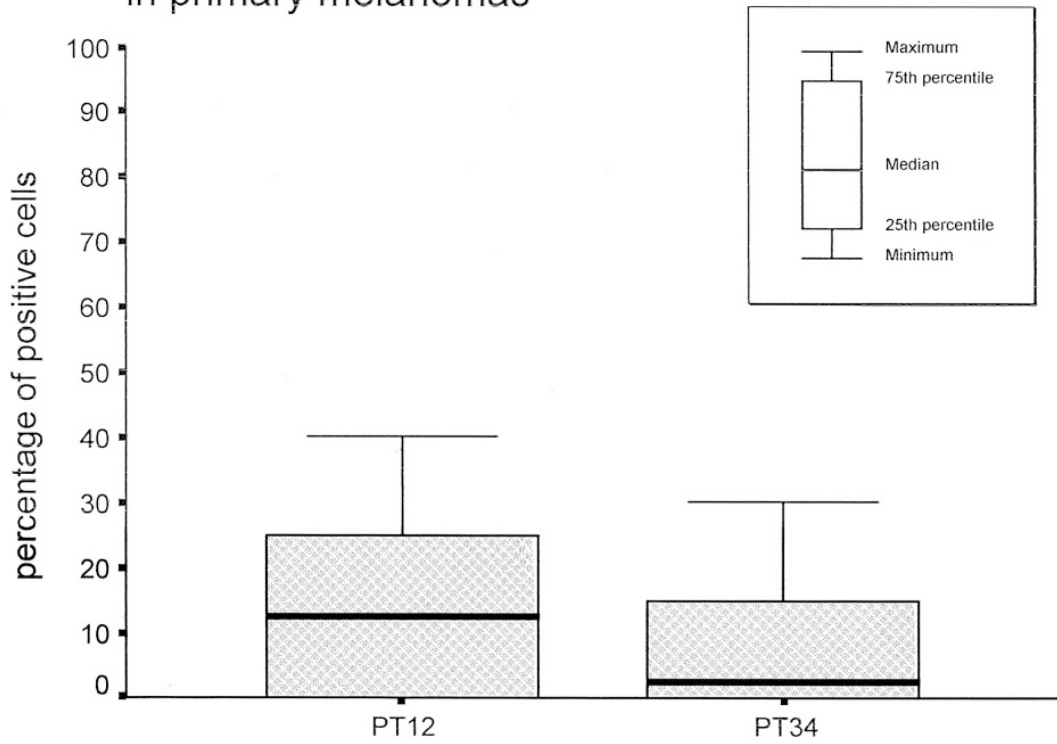

FIGURE 5. Box plot demonstrating the expression of Ku80 in primary melanomas classified according to WHO-pT. PT12, melanomas with thickness $<1.5 \mathrm{~mm}$; PT34, melanomas with thickness $>1.5 \mathrm{~mm}$. 

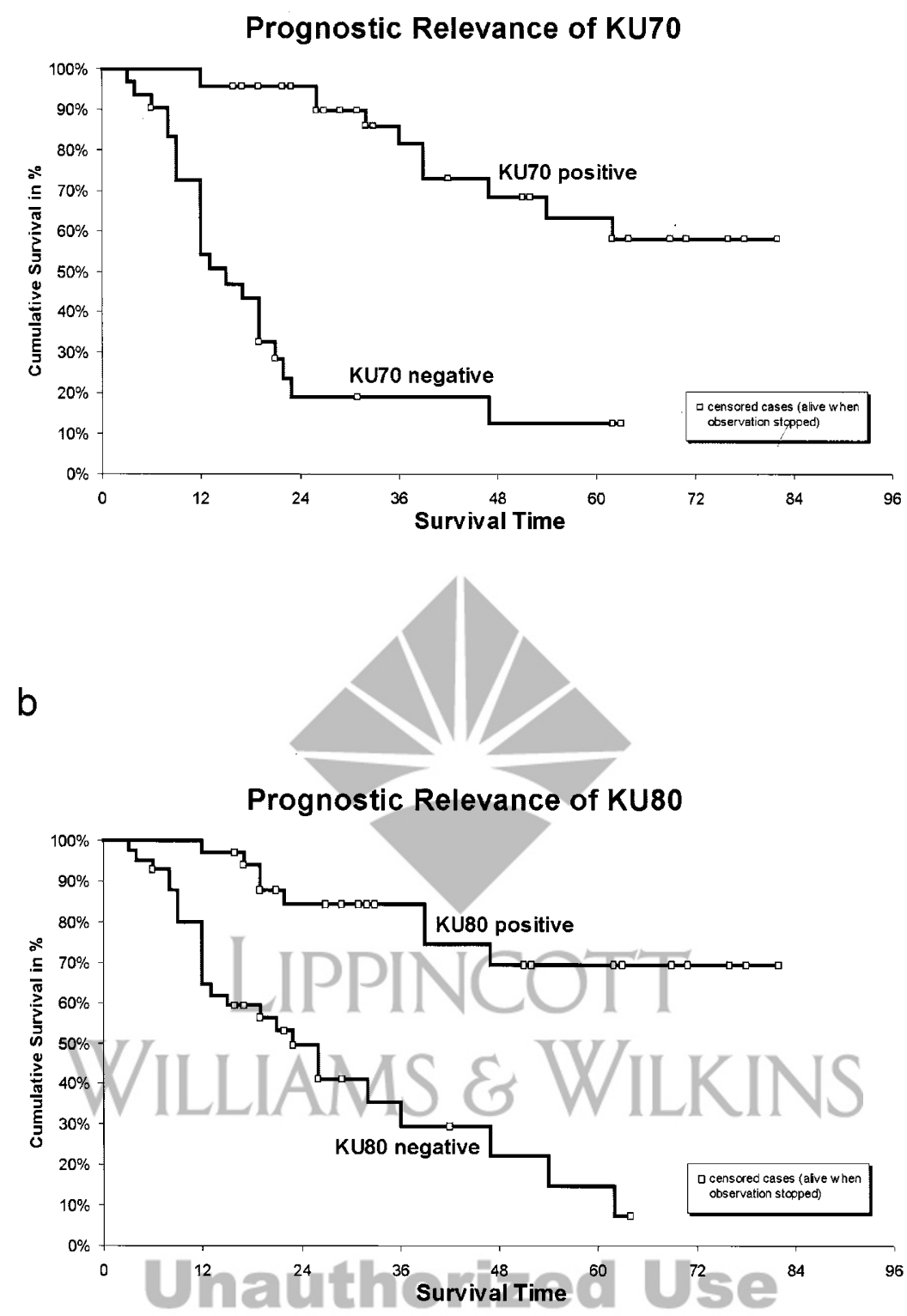

FIGURE 6. A, Kaplan-Meier survival curves of Ku70-positive $(n=45)$ and -negative $(n=31)$ melanomas. Difference between curves was highly significant $(P<.01)$. B, Kaplan-Meier survival curves of Ku80-positive $(n=34)$ and -negative $(n=42)$ melanomas. Comparison of survival rates demonstrated highly significant difference $(P<.01)$ between survival curves.

\section{Relation between Markers}

Highly significant correlations $(P<.01$ and $r>0.7)$ between Ku70 and Ku80 indices resulted from the calculations in the group of nevus cell nevi, lentigo maligna, and primary melanomas. In the other group investigated (melanoma metastases in lymph nodes and in vital organs), significant relations for marker expression were not found (Table 3).

\section{DISCUSSION}

The maintenance of genetic stability is in mammalian cells depends on the correct functioning of
DNA repair systems including DNA mismatch repair and double-strand repair pathways. The different mechanisms that control these processes actively work to correct these mistakes to eliminate genetic mutations. The diagnostic and prognostic relevance of DNA mismatch repair proteins in melanomas has been demonstrated by our research group in several studies (24-26).

In this study, we focused our attention on a DNA double-strand repair system with two caretaker genes, Ku70 and Ku80. Heterodimers of the 70- and $80-\mathrm{kDa} \mathrm{Ku}$ antigens are able to activate DNAdependent protein kinase (27). Mutations in any of 


\section{Prognostic Relevance of KU70 / KU80}

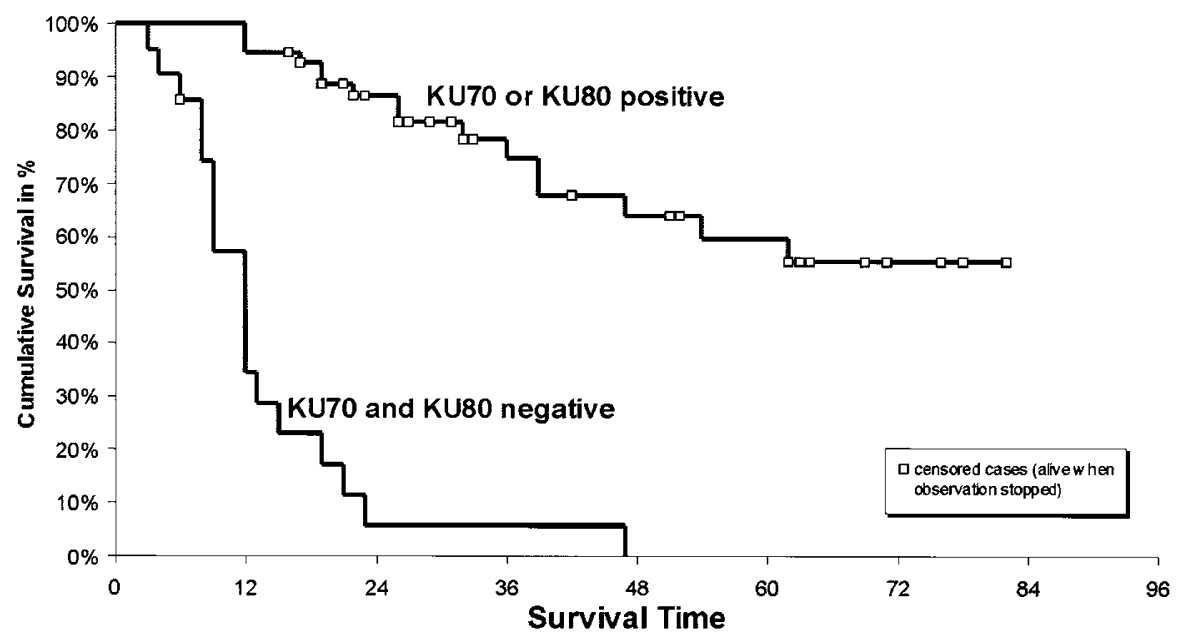

FIGURE 7. Kaplan-Meier survival curves of Ku70- and Ku80-negative melanomas $(n=21)$ and Ku70- or Ku80-positive tumors $(n=52)$. The difference in both cases was highly significant $(P<.01)$. Diagnostic Groups Investigated

\begin{tabular}{lc}
\hline \multicolumn{1}{c}{ Diagnosis } & Level of Significance \\
\hline Naevi & $\mathrm{XX}$ \\
Lentigo maligna & $\mathrm{XX}$ \\
Primary melanomas & $\mathrm{XX}$ \\
Lymphatic metastases & 0 \\
Organ metastases & 0 \\
\hline
\end{tabular}

$\mathrm{xx}$, highly significant correlation $(P<.01, r>0.7)$; $\mathrm{x}$, significant correlation $(P<.05, r>0.5)$; 0 , not significant correlation.
TABLE 3. Correlations between Ku70 and Ku80 in

\section{titop PPIN}

with that, quicker tumor progression. Mouse cells deficient for Ku80 displayed a marked increase in chromosomal aberrations, including breakage, translocations, and aneuploidy (30). Hypothetically, similar facts can influence patients" poor prognosis in human tumors.

In our study, both proteins showed only nuclear localization. This result is consistent with the observation of Kumaravel (7), although his study also reported cytoplasmic localization of Ku70 protein. Confocal microscopy on immunostained cells in the subunits of protein kinase increase their sensitivity to ionizing radiation and to DNA double-strand breaks.

The relation between Ku70 and Ku80 expression and radiosensitivity of tumors was demonstrated by Wilson et al. (28) in cervical carcinomas. The formerly mentioned study also shows the prognostic significance of Ku70 and Ku80 heterodimers.

In breast and bladder tumors, Ku70 and Ku80 heterodimer-binding activity was strongly reduced at the advanced tumor stage (29).

Down-regulation of both $\mathrm{Ku}$ antigens was generally observed along with melanoma progression. However, significant and highly significant differences were mostly found between the early stages of progression in pigmented tumors. Differences between primary melanomas and metastatic entities did not reach the level of statistical significance. This observation suggests that a defect of Ku70 and Ku80 genes plays a more important role in malignant transformation of nevus, lentigo, and malignant melanoma than in metastatic tumor spread.

In primary melanomas, loss of Ku70 and Ku80 expression negatively influenced the survival rate. We attribute this to an inability of tumor cells to repair DNA double-strand breaks and, connected combination with cell cycle analysis showed that $\mathrm{Ku} 70$ protein translocates to the cytoplasm after the G1 phase in irradiated cells. Our study did not find any cytoplasmic location. This fact can be explained by the different techniques applied or by the use of paraffin embedding and formalin fixation on the material investigated.

Ku70 and Ku80 proteins are functionally very closely related. Significant correlations between both markers were only found in the early stages of melanoma progression and primary melanomas. These correlations were no longer present in the diagnostic groups with metastases of the lymph nodes and vital organs. This fact indicates that dysregulation of the Ku70 and Ku80 axis may support metastatic tumor spread. Highly significant correlations between $\mathrm{Ku} 70$ and Ku80 expression were also demonstrated in cervical carcinomas (28).

In conclusion, the loss of expression of $\mathrm{Ku}$ proteins seems to accelerate the early entities of melanoma progression, whereby the functional connection between $\mathrm{Ku} 70$ and Ku80 proteins is preserved. In metastatic tumor spread, functional dysregulation seems to be of greater importance than the loss of expression. 


\section{REFERENCES}

1. Critchlow SE, Jackson SP. DNA end-joining: from yeast to man. Trends Biochem Sci 1998;23:394-8.

2. Baumann P, West SC. DNA end-joining catalyzed by human cell-free extracts. Proc Natl Acad Sci U S A 1998;95:14066-70.

3. Sekiguchi JA, Ferguson DO, Chen HT, Yang EM, Earle J, Frank K, et al. Genetic interactions between ATM and the nonhomologous end-joining factors in genomic stability and development. Proc Natl Acad Sci U S A 2001;98:3243-8.

4. Gao Y, Chadhuri J, Zhu C, Davidson L, Weaver DT, Alt FW. A targeted DNA-PKcs-null mutation reveals DNA-PKindependent functions for $\mathrm{Ku}$ in $\mathrm{V}(\mathrm{D}) \mathrm{J}$ recombination. Immunity 1998;9:367-76.

5. Jeggo PA. Identification of genes involved in repair of DNA double-strand breaks in mammalian cells. Radiat Res 1998; 150:S80-91.

6. Muller C, Rodrigo G, Calsou P, Sales B. DNA-dependent protein kinase: a major protein involved in the cellular response to ionizing radiation. Bull Cancer 1999;86:977-83.

7. Kumaravel TS, Bharathy K, Kudoh S, Tanaka K, Kamada N. Expression, localization and functional interactions of $\mathrm{Ku} 70$ subunit of DNA-PK in peripheral lymphocytes and Nalm-19 cells after irradiation. Int J Radiat Biol 1998;74:481-9.

8. Takata M, Sasaki MS, Sonoda E, Morrison C, Hashimoto M, Utsumi $\mathrm{H}$, et al. Homologous recombination and nonhomologous end-joining pathways of DNA double strand break repair have overlapping roles in the maintenance of chromosomal integrity in vertebrate cells. EMBO J 1998;17: 5497-508.

9. Li GC, Ouyang H, Li X, Nagasawa H, Little JB, Chen DJ, et al. Ku70: a candidate tumor suppressor gene for murine $\mathrm{T}$ cell lymphoma. Mol Cell 1998;2:1-8.

10. Lee ST, Moore JK, Holmes A, Umezu K, Kolodner RD, Haber JE. Saccharomyces Ku70, mre11/rad50 and RPA proteins regulate adaptation to $\mathrm{G} 2 / \mathrm{M}$ arrest after DNA damage. Cell 1998;94:399-409.

11. Frit P, Canitrot Y, Muller C, Foray N, Calsou P, Marangoni E. Cross-resistance to ionizing radiation in murine leukemic cell line resistant to cis-dichlorodiammineplatinum, role of Ku autoantigen. Mol Pharmacol 1999;56:141-6. 1)

12. Shen H, Schultz M, Kruh GD, Tew KD. Increased expression of DNA-dependent protein kinase confers resistance to Adriamycin. Biochim Biophys Acta 1998;1381:131-8.

13. Lynch EM, Moreland RB, Ginis I, Perrine SP, Faller DV. Hypoxia-activated ligand HAL-1/13 is lupus autoantigen Ku80 and mediates lymphoid cell adhesion in vitro. Am J Physiol Cell Physiol 2001;280:C897-911.

14. Reeves WH, Sthoeger ZM. Molecular cloning of cDNA en coding the p70 $(\mathrm{Ku})$ lupus autoantigen. J Biol Chem 1989; 264:5047-52.

15. Elwood JM, Gallagher RP, Hill GB. Cutaneous melanoma in relation to intermittent and constant sun exposure-the
Western Canada melanoma study. Int J Cancer 1985;35:42733.

16. Vagero D, Ringback C, Kiviranta H. Melanoma and others tumours of the skin among office, other indoor and outdoor workers in Sweden 1961-1979. Br J Cancer 1986;53: 507-12.

17. Kaskel P, Sander S, Kron M, Kind P, Peter RU, Krahn G. Outdoor activities in childhood: a protective factor for cutaneous melanoma? Results of a case-control study in 271 matched patients. Br J Dermatol 2001;145:602-9.

18. Armstrong BK, Kricker A. The epidemiology of UV induced skin cancer. J Photochem Photobiol B 2001;63:8-18.

19. Bergenmar M, Brandberg Y. Sunbathing and sun-protection behaviors and attitudes of young Swedish adults with hereditary risk for malignant melanoma. Cancer Nurs 2001;24: 341-50.

20. Scherschun L, Lim HW. Photoprotection by sunscreens. Am J Clin Dermatol 2001;2:131-4.

21. Breslow A. Thickness, cross-sectional areas and depth of invasion in the prognosis of cutaneous melanoma. Ann Surg 1979;172:902-8.

22. Kaplan EL, Meier P. Nonparametric estimation from incomplete observations. J Am Stat Assoc 1988;53:457-60.

23. Cox DR. Regression models and life tables. J Stat Soc B 1972;34:187-220.

24. Korabiowska M, Ruschenburg I, Schlott T, Brinck U, Kubitz A, Droese M. Relation between ploidy status and the expression of the DNA mismatch repair genes in cytological specimens of melanoma metastases. Diagn Cytopathol 2000;24: 157-62.

25. Korabiowska M, Brinck U, Dengler H, Stachura J, Schauer A, Droese M. Analysis of the DNA mismatch repair in malignant melanomas. Anticancer Res 2000;20:4499-506.

26. Korabiowska M, Brinck U, Kotthaus I, Berger H, Droese M. Comparative study of DNA mismatch repair genes, APC and GADD genes in melanoma recurrences and metastases. Melanoma Res 2000;10:537-44.

27. Zhao HJ, Hosoi Y, Miyachi H, Ishii K, Yoshida M, Nemoto K, et al. DNA-dependent protein kinase activity correlates with Ku70 expression and radiation sensitivity in esophageal cancer cell lines. Clin Cancer Res 2000;6:1073-8.

28. Wilson CR, Davidson SE, Margison GP, Jackson SP, Hendry JH, West CM. Expression of Ku70 correlates with survival in carcinoma of the cervix. Br J Cancer 2000;83:1702-6.

29. Pucci S, Mazzarelli P, Rabitti G, Giai M, Gallucci M, Flammia G, et al. Tumor specific modulation of Ku70/80 DNA binding activity in breast and bladder human tumour biopsies. On=cogene 2001;20:739-47.

30. Difilipantonio MJ, Zhu J, Chen HT, Meffre E, Nussenzweig MC, Max EE, et al. DNA repair protein KU80 suppresses chromosomal aberrations and malignant transformation. Nature 2000;404:510-4. 